\title{
Oronasal versus Nasal Masks for Non-Invasive Ventilation in COPD: A Randomized Crossover Trial
}

This article was published in the following Dove Press journal:

International Journal of Chronic Obstructive Pulmonary Disease

\author{
Daniel S Majorski $\mathbb{D}^{\prime}$ \\ Jens C Callegari' \\ Sarah B Schwarz (D) \\ Friederike S Magnet (1D' \\ Rodion Majorski ${ }^{2}$ \\ Jan H Storre (D) $^{3,4}$ \\ Claudia Schmoor ${ }^{5}$ \\ Wolfram Windisch (ID) \\ 'Cologne Merheim Hospital, Department \\ of Pneumology, Kliniken der Stadt Köln \\ $\mathrm{gGmbH}$, Witten/Herdecke University, \\ Cologne, Germany; ${ }^{2}$ Department of \\ Neurology and Neurophysiology, Helios \\ Hospital Wuppertal, Witten/Herdecke \\ University, Wuppertal, Germany; ${ }^{3}$ Praxis \\ Pneumologie Solln, Munich, Germany; \\ ${ }^{4}$ Department of Pneumology, University \\ Medical Hospital, Freiburg, Germany; \\ ${ }^{5}$ Clinical Trials Unit, Medical Center - \\ University Medical Hospital, Freiburg, \\ Germany
}

Purpose: The impact of oronasal and nasal masks on the quality of nocturnal non-invasive ventilation (NIV) needs to be clarified. This trial was designed to compare the impact of oronasal and nasal masks on the objective quality and subjective acceptance of nocturnal NIV in COPDpatients.

Patients and Methods: In a randomized crossover trial, 30 COPD-patients with wellestablished high-intensity NIV (mean inspiratory/expiratory positive airway pressure $26 \pm 3 / 5$ $\pm 1 \mathrm{cmH}_{2} \mathrm{O}$, mean respiratory back-up rate $17 \pm 1 / \mathrm{min}$ ) were ventilated for two consecutive nights on oronasal and nasal masks, respectively.

Results: Full polysomnography, nocturnal blood gas measurements, and subjective assessments were performed. There was a tendency towards improved sleep efficiency (primary outcome) when an oronasal mask was worn (+9.9\%; 95\% CI:-0.2\%-20.0\%; $P=0.054)$. Sleep stages $3 / 4$ were favored by the oronasal mask $(+12.7 \%$; $95 \% \mathrm{CI}: 6.0 \%-19.3 \% ; P=<0.001)$. Subjective assessments were comparable with the exception of items related to leakage $\left(P<0.05\right.$ in favor of nasal masks). The mean transcutaneous $\mathrm{PCO}_{2}$ value for oronasal masks $(47.7 \pm 7.4 \mathrm{mmHg})$ was comparable to that of nasal masks $(48.9 \pm 6.6 \mathrm{mmHg})$ $(P=0.11)$. There was considerable diversity amongst individual patients in terms of sleep quality and gas exchange following mask exchange. Subjective mask preference was not associated with sleep quality, but with nocturnal dyspnea. Over $40 \%$ of patients subsequently switched to the mask that they were not previously accustomed to.

Conclusion: In general, oronasal and nasal masks are each similarly capable of successfully delivering NIV in COPD-patients. However, the individual response to different interfaces is extremely heterogeneous, while subjective mask preference is independent from objective measures, but associated with dyspnea.

Trial Registration: German Clinical Trials Registry (DRKS00007741).

Keywords: respiratory insufficiency, sleep, masks, dyspnea

\section{Introduction}

Long-term non-invasive ventilation (NIV) has been used in chronically hypercapnic COPD patients since the 1990s. ${ }^{1-3}$ Based on current evidence, the guidelines for the use of long-term home NIV in COPD patients by the European Respiratory Society (ERS) now provide conditional support for the application of long-term NIV to improve health outcomes. ${ }^{4}$ This recommendation is reportedly valid for patients with both chronic stable hypercapnic COPD and persistent hypercapnia, in whom a life-threatening episode of acute hypercapnic respiratory failure occurred and acute NIV therapy was required. ${ }^{4}$

The ERS guidelines also suggest titrating long-term NIV to normalize or reduce $\mathrm{PaCO}_{2}$ levels in these patients. This is best achieved through high ventilator
Correspondence: Wolfram Windisch Department of Pneumology, Cologne Merheim Hospital, Kliniken der Stadt Köln gGmbH, Witten/Herdecke University, Faculty of Health/School of Medicine, Ostmerheimer Strasse 200, Köln, D-5I 109, Germany

Email windischw@kliniken-koeln.de
International Journal of Chronic Obstructive Pulmonary Disease 2021:|6 77|-78| 
settings, particularly by increasing inspiratory positive airway pressures and increasing respiratory rate, an approach that has been described as high-intensity NIV (HI-NIV). ${ }^{2-6}$ It is worth noting that the ventilation interface is deemed to be technically crucial for the successful delivery of long-term NIV in COPD patients..$^{2-4}$ Previous studies have also shown that there is no clear difference between oronasal and nasal masks regarding the quality of nocturnal ventilation, ${ }^{7,8}$ although these studies were performed in heterogeneous patient cohorts, and NIV was performed in a less aggressive manner using considerably lower ventilator settings than those applied in HI-NIV.

Nowadays, most patients with COPD receive oronasal masks for NIV, ${ }^{4,9,10}$ which is in stark contrast to what was reported 15 years ago, when nasal masks were the most common type prescribed. ${ }^{11}$ Even though there is no clear evidence to support this change in mask preference by the prescribing physicians, an explanation for the abovementioned observation could be that an ever-increasing number of COPD patients are receiving long-term NIV therapy following acute NIV treatment in hospital. ${ }^{4,9,12}$ This is where the proper handling of mouth leakage is thought to form an integral part of successful NIV during COPD exacerbation. ${ }^{2,3,9,10}$

Both nasal masks and oronasal masks have been successfully used in the past to deliver HI-NIV, ${ }^{6,13,14}$ although no randomized controlled trials have been performed thus far to compare these two different interfaces in COPD patients. However, HI-NIV is reportedly associated with significant leakage, ${ }^{13}$ which can occur either via an open mouth (mouth leakage) or the mask itself, which is not fitted in an airtight manner (mask leakage). Thus, the choice of interface, especially during HI-NIV, is suggested to affect the degree of leakage as well as subsequent sleep quality and gas exchange, all of which ultimately determine the quality of nocturnal NIV. For this reason, the impact of the interface not only on sleep quality and gas exchange, but also on the patient preferences suggested by the ERS guidelines, ${ }^{4}$ needs to be clearly established.

The present study aimed to compare the impact of nasal versus oronasal masks on sleep quality and nocturnal gas exchange in patients receiving HI-NIV for the treatment of chronic hypercapnic respiratory failure due to COPD. A crossover randomized trial was set up for this purpose.

\section{Patients and Methods}

The study protocol was approved by the ethics committee at Witten/Herdecke University. The study was performed in accordance with the ethical standards laid down in the Declaration of Helsinki and was registered at the German Clinical Trials Registry (DRKS00007741). The study was undertaken at the Department of Pneumology, Lung Clinic, Cologne Merheim Hospital, Witten/Herdecke University, Germany.

\section{Inclusion and Exclusion Criteria}

COPD patients with moderate to severe airflow limitation were included in the study as defined by GOLD Guidelines. ${ }^{15,16}$ Patients needed to have been on NIV for at least one month prior to inclusion, and in a stable disease state without any signs of acute respiratory failure ( $\mathrm{pH}<7.35$ ), respiratory infection, or worsening of symptoms during the preceding month. Patients with a body mass index $(\mathrm{BMI}) \geq 35 \mathrm{~kg} / \mathrm{m}^{2}$ were excluded from the study in order to prevent the inclusion of overlap patients predominantly suffering from obesity hypoventilation syndrome. ${ }^{17,18}$ Upon meeting all inclusion criteria, patients were approached by a respiratory physician. Informed written consent was obtained from all subjects.

\section{Measurements}

Participants underwent body plethysmography, ${ }^{19}$ COdiffusion capacity tests and capillary blood gas analyses. Furthermore, each patient was monitored by polysomnography (PSG) to assess sleep quality and efficiency during the interventions. ${ }^{20,21}$ This was supplemented by overnight transcutaneous $\mathrm{PCO}_{2}$ monitoring $\left(\mathrm{PtcCO}_{2}\right)$ proving evidence for alveolar ventilation. Satisfaction with mask interface, sensation of dyspnea, mouth dryness and comfort were assessed subjectively via survey.

\section{Study Design}

The study had a randomised, open-label, two-treatment, two-period crossover design for comparison of nasal masks and oronasal masks with respect to sleep quality and nocturnal gas exchange. Patients were randomised to receive the masks either in the sequence of nasal mask in the first measurement night followed by oronasal mask in the second measurement night the following day, or oronasal followed by nasal. Acclimatization to either interface was carried out during daytime prior to the measurement night with the corresponding mask. Mask adaption was carried out by a specially trained respiratory therapist with individual adaptation to each patient's need. No chinstraps were made use of, when dealing with nasal mask interface. Despite the prospective design of the trial, a conscious 
decision was made against fixed mask models for nasal and oronasal interface as this trial targeted to achieve reallife conditions, as experience showed, that one interface does not fit all patients. It was therefore decided to choose commercially available models only. No changes to medication were made, and participants did not take any hypnotic or antidepressant drugs, sleep medication, or alcohol prior to the sleep trials. Full PSG and $\mathrm{PtcCO}_{2}$ monitoring as well as early-morning blood gas analyses were performed during both nights whilst the patient was on the ventilator. Following the 2-night sleep trial, patients were required to answer a specifically developed survey (12 items using a $100 \mathrm{~mm}$ Visual analogue scale (VAS), higher score $=$ does apply; lower score $=$ does not apply) regarding their level of satisfaction with the interfaces.

\section{Analysis}

Sleep efficiency served as the primary outcome. The secondary outcomes were: (i) mean nocturnal $\mathrm{PtcCO}_{2}$, (ii) the percentage of slow-wave sleep (stages 3 and 4), (iii) the percentage of REM sleep, and (iv) the results of the specifically designed patient survey, depicted on a $100 \mathrm{~mm}$ VAS, from which mask preferences and the associated factors were analysed.

The sample-size calculation was based on the primary endpoint of sleep efficiency. The study was planned to show a difference between the two interfaces at a twosided significance level of 0.05 with a power of $90 \%$, using the assumption that a minimal clinically relevant difference in sleep efficiency of $8 \%$ is present, as previously proposed. ${ }^{8}$ Based on previous studies, we estimated the standard deviation of the difference in sleep efficiency between the two interfaces to be $12.5 \%{ }^{22}$ Using these assumptions, a sample-size of 28 randomized patients was required under the crossover design. All values are shown as mean $\pm \mathrm{SD}$ unless stated otherwise.

Further details on measurements, sleep studies, NIV, study design and analysis are provided in the online data supplement.

\section{Results}

A total of 44 COPD patients with long-term HI-NIV were screened, and 34 of these were consecutively randomized to one of the two intervention groups. Thirty patients completed both parts of the trial (Figure 1). Demographic data, blood gases, basic lung function data and ventilator settings are presented in Table 1. More detailed data on the body plethysmography measurements are displayed in the online data (E-Table 1). Further information about the different ventilators and interfaces used for HI-NIV is outlined in the online data (E-Table 2). For the exhalation system, 7 and 23 patients used active valve and passive leak port circuits, respectively. Active humidification was used in 22 patients, while humidification was not provided in 8 patients. Finally, 24 patients received long-term oxygen therapy in addition to HI-NIV, with a mean oxygen flow rate of $2.4 \pm 1.3 \mathrm{~L} / \mathrm{min}$. Apnea-Hypopnea Index measured via PSG was 3.6 \pm 8.1 events/hour for patients using oronasal mask and $3.4 \pm 8.9$ for patients using nasal mask.

The results of the nocturnal assessments for each of the two mask-sequence interventions are compared in Table 2. In terms of the primary endpoint, there was a clinically relevant difference in sleep efficiency of $>8 \%$ (as established in previous trials) $(9.9 \%$; 95\% CI: $[-0.2 \% ; 20.0 \%])$ in favor of the oronasal mask (Table 2, Figure 2A), but this did not reach statistical significance $(p=0.0537)$. In addition, there was a statistically significant difference in the relative amount of slow-wave sleep $(12.7 \%, 95 \% \mathrm{CI}$ $[6.0 \% ; 19.3 \%], P=0.0005)$ in favor of the oronasal interface (Table 2, Figure 2B).

Figure 3 presents the individual data for sleep efficiency (primary outcome) in relation to the interface the patient was familiar with at study inclusion. Accordingly, patients who had previously used nasal masks on a regular basis showed no relevant change in mean sleep efficiency when they switched to an oronasal mask (Figure 3A). In contrast, patients who had regularly used an oronasal mask prior to the study showed a significant deterioration in mean sleep efficiency when they switched to a nasal mask (Figure 3B). However, from an individual perspective, there was a broad variety of changes in sleep efficiency when the switch was made from one interface to the other (Figures 3A and B).

Subjective evaluation of sleep showed no differences related to the type of mask, with the exception of items dealing with leakage, which were rated in favor of nasal masks (Figure 4, E-Table 3). Due to subjective preference, 9 out of the 21 patients who used an oronasal mask prior to the study decided to switch to a nasal mask after the study $(42,8 \%)$, while 4 out of 9 patients who were previously established on a nasal mask decided to switch to an oronasal mask thereafter $(44,4 \%)$ (E-Table 4). Differences in the subjective evaluation of sleep (mean of all 12 items) in terms of nasal versus oronasal masks were not correlated with differences in sleep efficiency $(r=0.247 ; P=0.19$; Figure E1). Finally, the patient's preferred choice of 


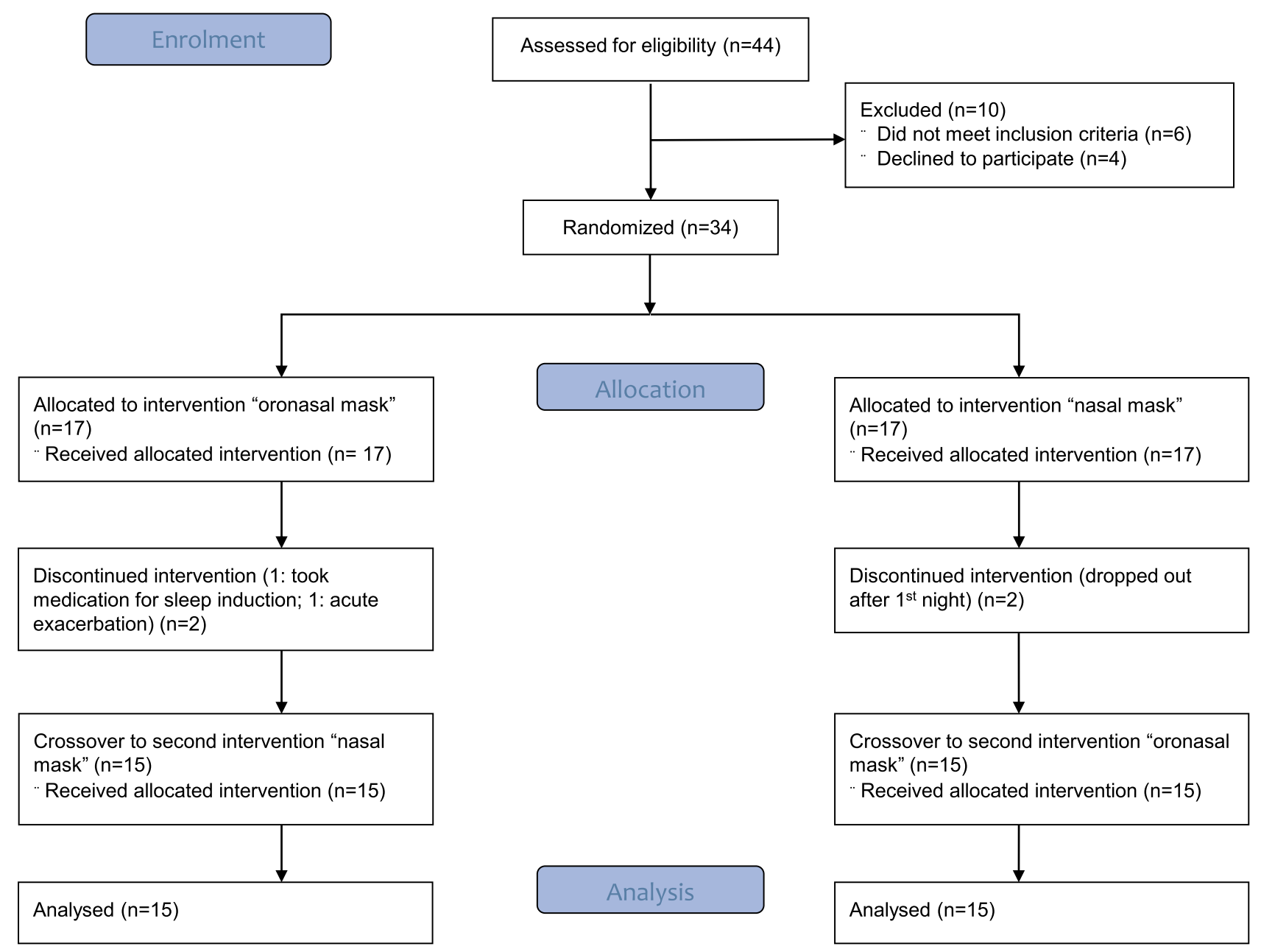

Figure I CONSORT flow diagram of the study enrollment process. ${ }^{25}$

interface was independent of differences in both sleep efficiency (Figure E2a) and nocturnal $\mathrm{PtcCO}_{2}$ when the two interfaces were compared (Figure E2b). In contrast, patients decided to continue with the interface that was associated with a lower frequency of dyspnea, as illustrated in Figure 5.

\section{Discussion}

This is the first randomized crossover trial to compare two different interfaces used for HI-NIV in COPD-patients. The interfaces were comparatively assessed in terms of their impact on various aspects of sleep quality and alveolar ventilation.

In terms of the primary outcome, there was a trend towards improved sleep efficiency when an oronasal instead of a nasal mask was used during nocturnal NIV. The estimated difference between masks of nearly $10 \%$ was even larger than the assumed clinically relevant difference of $8 \%$, which was established during sample size calculation for the study. At the 5\% level of statistical significance, sleep efficiency was not found to differ in relation to the type of mask used. This was due to the large confidence interval, which resulted from an observed standard deviation of about $27 \%$ and was hence much larger than the value of $12.5 \%$ that was established during the planning of the study. ${ }^{22}$

In addition, while the two interfaces each had a similar impact on oxygenation, alveolar ventilation, early-morning blood gases, and numerous parameters of sleep quality, the oronasal mask had a more favorable association with the relative proportion of stage-3/4 sleep, although it needs to be addressed, that this was a two-night trial, and this finding needs to be addressed in further larger trials. Furthermore, we found that more patients deteriorated severely in terms of sleep efficiency when switching from an oronasal to a nasal mask, as against to patients switching from a nasal to an oronasal interface, which 
Table I Patient Characteristics at Baseline

\begin{tabular}{|c|c|}
\hline Characteristics & $n=30$ \\
\hline Age [years] & $64.9 \pm 8.8$ \\
\hline Female sex [\%] & $63.3 \%$ \\
\hline FEV , after bronchodilation [\%pred] & $33.5 \pm 12.9$ \\
\hline FVC [\%pred] & $52.5 \pm 13.9$ \\
\hline $\mathrm{FEV}_{\mathrm{I}} / \mathrm{FVC}$ ratio [\%pred] & $50.9 \pm 18.3$ \\
\hline TLC [\%pred] & $114.2 \pm 23.2$ \\
\hline RV [\%pred] & $185.9 \pm 79.5$ \\
\hline Cumulative smoking dosage [pack years]* & $52.7 \pm 27.9$ \\
\hline BMI $\left[\mathrm{kg} / \mathrm{m}^{2}\right]$ & $25.6 \pm 5.9$ \\
\hline $\mathrm{pH}$ & $7.39 \pm 0.03$ \\
\hline $\mathrm{PaO}_{2}[\mathrm{mmHg}]$ & $68.1 \pm 13.4$ \\
\hline $\mathrm{PaCO}_{2}[\mathrm{mmHg}]$ & $48 \pm 6.5$ \\
\hline $\mathrm{HCO}_{3}{ }^{-}[\mathrm{mmol} / \mathrm{l}]$ & $27.5 \pm 3.2$ \\
\hline IPAP $\left[\mathrm{cmH}_{2} \mathrm{O}\right]$ & $26 \pm 2.6$ \\
\hline EPAP $\left[\mathrm{cmH}_{2} \mathrm{O}\right]$ & $5.3 \pm 0.9$ \\
\hline Backup frequency [/min] & $17 \pm 1$ \\
\hline
\end{tabular}

Note: $* 23$ patients were ex-smokers $(77 \%)$ and 7 patients were current smokers $(23 \%)$. Abbreviations: $\mathrm{FEV}_{1}$, forced expiratory volume in I second; FVC, forced vital capacity; RV, residual volume; TLC, total lung capacity; BMI, body mass index; $\mathrm{PaO}_{2}$. partial pressure of arterialized oxygen; $\mathrm{PaCO}_{2}$, partial pressure of arterialized carbon dioxide; $\mathrm{HCO}_{3}{ }^{-}$, arterialized standard hydrogen carbonate; IPAP, inspiratory positive airway pressure; EPAP, expiratory positive airway pressure.

might have led to the detected difference in sleep efficiency. In total, no clear advantage of either the oronasal or nasal mask was found with regard to the objectively assessed quality of nocturnal ventilation.

Major findings of this trial were as follows:

Firstly, there was broad diversity amongst individual patients concerning the differences between the two interfaces, and this held true for both subjective and objective assessments. Even though most of the mean outcomes only differed slightly between the two interfaces, the individual changes were substantial in some patients, reflecting both improvements and deteriorations following the change of interface; this was independent of the primary interface the patient was already accustomed to. Interestingly, more than $40 \%$ of the study participants ultimately preferred the alternative mask for the continuation of HI-NIV at home when compared to the mask they were accustomed to, and again, this was irrespective of the type of the interface.

Secondly, subjective evaluation of sleep quality did not show an obvious overall benefit of either interface, with the exception that the nasal mask appeared to be advantageous for events related to nocturnal leakage. In addition, subjective evaluation of sleep was independent of objectively assessed sleep quality when the different interfaces were compared. More importantly, the preferred choice of interface by patients was not dependent on sleep efficiency or gas exchange, but was highly associated with the occurrence of dyspnea during nocturnal NIV.

The current findings have potential clinical significance. In the first instance, both the nasal and oronasal mask generally appear to be similarly capable of delivering HI-NIV to COPD patients. However, from an individual standpoint, the choice of interface substantially influences the quality of nocturnal ventilation in terms of both subjective and objective parameters. From this data, it can be concluded that both types of interface should be tested in each individual patient. This could be especially relevant if NIV is not effective or not particularly well tolerated under the use of a specific interface, whereas the alternative interface has the individual potential to be much more effective and/or better tolerated.

The current findings are partly in contrast to previous trials investigating the different interfaces concerning their impact on nocturnal ventilation and sleep efficiency. ${ }^{8}$ Both, the trial by Wilson et al and the current one showed that both interfaces are equally applicable in term of gas exchange. In terms of sleep efficiency there were diverging results. Wilson et al showed a better sleep efficiency under nasal mask, whereas the current trial showed an improvement under oronasal interface. A possible explanation might be the diverse patient selection in the aforementioned trial, where 18 patients were included with 6 different underlying diseases. Furthermore, all patients in the trial by Wilson et al were used to a nasal interface prior to inclusion.

Previous randomized crossover trials comparing different ventilatory modes for NIV in COPD and non-COPD patients have also shown that there are no clear overall differences in the quality of nocturnal ventilation. This was the case when pressure was compared to volume preset ventilation $^{23,24}$ and classical fixed-pressured ventilation was compared to target volume ventilation; ${ }^{14}$ however, the extent of individual differences in both sleep quality and nocturnal gas exchange was substantial and similar to what was observed in the current study. Therefore, not only the technical aspects of long-term NIV, such as the type of the ventilatory mode, but also the interface, need to be carefully addressed in individual patients.

The ERS guidelines for long-term home NIV in COPD patients recently defined sleep quality and gas exchange, amongst other factors, as non-critical outcomes that would not take priority in subsequent guideline decision-making. On the other hand, dyspnea as 
Table 2 Results of the Blood Gas Analyses, Transcutaneous $\mathrm{PCO}_{2}$ Monitoring, Pulse Oximetry and Polysomnography for Each Group

\begin{tabular}{|c|c|c|c|c|c|}
\hline & Period & Nasal Mask & Oronasal Mask & Treatment Effect $(95 \% \mathrm{Cl})$ & $P$-value \\
\hline $\mathrm{SaO}_{2}$ minimum [\%] & $\begin{array}{l}1 \\
2\end{array}$ & $\begin{array}{l}83 \pm 7.3 \\
86.2 \pm 4\end{array}$ & $\begin{array}{l}85.3 \pm 6.1 \\
81.7 \pm 8.8\end{array}$ & $-1.2(-3.9 ; 1.6)$ & 0.4 \\
\hline $\mathrm{SaO}_{2}$ mean [\%] & $\begin{array}{l}1 \\
2\end{array}$ & $\begin{array}{c}94 \pm 3.6 \\
93.6 \pm 2.2\end{array}$ & $\begin{array}{c}94 \pm 2.8 \\
94.6 \pm 2.8\end{array}$ & $0.5(-0.97 ; 1.96)$ & 0.5 \\
\hline $\mathrm{PaCO}_{2}[\mathrm{mmHg}]$ & $\begin{array}{l}1 \\
2\end{array}$ & $\begin{array}{c}47.1 \pm 6.9 \\
50 \pm 5.3\end{array}$ & $\begin{array}{c}47.8 \pm 4.8 \\
45.8 \pm 7\end{array}$ & $-1.5(-3.3 ; 0.4)$ & 0.11 \\
\hline $\mathrm{PaO}_{2}[\mathrm{mmHg}]$ & $\begin{array}{l}1 \\
2\end{array}$ & $\begin{array}{c}78.6 \pm 22.3 \\
69.5 \pm 16\end{array}$ & $\begin{array}{l}70.2 \pm 10.1 \\
76.4 \pm 23.1\end{array}$ & $-0.5(-6.7 ; 5.6)$ & 0.86 \\
\hline $\mathrm{pH}$ & $\begin{array}{l}1 \\
2\end{array}$ & $\begin{array}{l}7.4 \pm 0.05 \\
7.4 \pm 0.03\end{array}$ & $\begin{array}{l}7.4 \pm 0.04 \\
7.4 \pm 0.05\end{array}$ & $0.01(-0.002 ; 0.02)$ & 0.11 \\
\hline $\mathrm{HCO}_{3}^{-}[\mathrm{mmol} / /]$ & $\begin{array}{l}1 \\
2\end{array}$ & $\begin{array}{l}28.6 \pm 2.7 \\
28.4 \pm 2.9\end{array}$ & $\begin{array}{c}27.8 \pm 2.3 \\
29 \pm 3.2\end{array}$ & $-0.01(-0.7 ; 0.7)$ & 0.97 \\
\hline $\mathrm{P}_{\mathrm{tc}} \mathrm{CO}_{2}$ mean $[\mathrm{mmHg}]$ & $\begin{array}{l}1 \\
2\end{array}$ & $\begin{array}{c}49.8 \pm 8 \\
48.1 \pm 5.1\end{array}$ & $\begin{array}{l}46.5 \pm 8.7 \\
48.8 \pm 6.4\end{array}$ & $-1.2(-3.6 ; 1.1)$ & 0.29 \\
\hline Sleep efficiency [\%] & $\begin{array}{l}1 \\
2\end{array}$ & $\begin{array}{c}49.5 \pm 20.7 \\
51.4 \pm 30\end{array}$ & $\begin{array}{l}57.6 \pm 19.4 \\
63.1 \pm 20.7\end{array}$ & $9.9(-0.2 ; 19.9)$ & 0.0537 \\
\hline Total sleep time [min] & $\begin{array}{l}1 \\
2\end{array}$ & $\begin{array}{l}210.3 \pm 105.9 \\
243.8 \pm 116.8\end{array}$ & $\begin{array}{c}231.3 \pm 82.3 \\
267.3 \pm 119.2\end{array}$ & $22.2(-20 ; 64.5)$ & 0.29 \\
\hline Sleep latency [min] & $\begin{array}{l}1 \\
2\end{array}$ & $\begin{array}{l}49.3 \pm 38.2 \\
34.1 \pm 25.7\end{array}$ & $\begin{array}{l}46.5 \pm 43.9 \\
43.4 \pm 42.7\end{array}$ & $3.7(-14.7 ; 22.3)$ & 0.68 \\
\hline Sleep Stage I/2 [\%] & $\begin{array}{l}1 \\
2\end{array}$ & $\begin{array}{c}56.9 \pm 26 \\
52.6 \pm 23.3\end{array}$ & $\begin{array}{l}49.7 \pm 18.1 \\
47.4 \pm 21.1\end{array}$ & $-6.2(-15.9 ; 3.5)$ & 0.2 \\
\hline Sleep Stage I/2 [min] & $\begin{array}{l}1 \\
2\end{array}$ & $\begin{array}{l}120.9 \pm 66.9 \\
119.7 \pm 70.4\end{array}$ & $\begin{array}{c}110.9 \pm 55 \\
|25 .| \pm 62.9\end{array}$ & $-2.3(-30.3 ; 25.6)$ & 0.87 \\
\hline Stage $3 / 4$ [\%] & $\begin{array}{l}1 \\
2\end{array}$ & $\begin{array}{l}20.1 \pm 21.9 \\
24.0 \pm 15.9\end{array}$ & $\begin{array}{c}35.6 .5 \pm 17.2 \\
33.9 \pm 26.1\end{array}$ & $12.7(6.0 ; 19.3)$ & 0.0005 \\
\hline Stage $3 / 4$ [min] & $\begin{array}{l}1 \\
2\end{array}$ & $\begin{array}{c}50 \pm 58 \\
66.4 \pm 49.3\end{array}$ & $\begin{array}{c}79.9 \pm 45.7 \\
89.7 \pm 90\end{array}$ & $26.6(-3.3 ; 56.4)$ & 0.08 \\
\hline REM [\%] & $\begin{array}{l}1 \\
2\end{array}$ & $\begin{array}{c}10.1 \pm 9.2 \\
13 \pm 9.8\end{array}$ & $\begin{array}{c}\mid I \pm 5.8 \\
|4.6 \pm 9 .|\end{array}$ & $1.3(-2.6 ; 5.1)$ & 0.51 \\
\hline REM [min] & $\begin{array}{l}1 \\
2\end{array}$ & $\begin{array}{l}26.8 \pm 27.5 \\
34.8 \pm 29.6\end{array}$ & $\begin{array}{c}29.2 \pm 20 \\
42.5 \pm 27.3\end{array}$ & $5(-4.6 ; 14.7)$ & 0.29 \\
\hline Arousals [/h] & $\begin{array}{l}1 \\
2\end{array}$ & $\begin{array}{c}21.6 \pm 21.9 \\
15.3 \pm 9.3\end{array}$ & $\begin{array}{l}16.7 \pm 20.6 \\
16.8 \pm 15.9\end{array}$ & $-3.4(-38.5 ; 38.3)$ & 0.99 \\
\hline
\end{tabular}

Note: All values are mean \pm SD if not stated otherwise.

Abbreviations: $\mathrm{SaO}_{2}$, arterialized oxygen saturation; $\mathrm{PaCO}_{2}$, partial pressure of arterialized carbon dioxide; $\mathrm{PaO} 2$, partial pressure of arterialized oxygen; $\mathrm{HCO}{ }_{3}{ }^{-}$, arterialized standard hydrogen carbonate; $\mathrm{P}_{\mathrm{tc}} \mathrm{CO}_{2}$, partial pressure of transcutaneous carbon dioxide; REM, rapid eye movement.

well as mortality, hospitalization, exacerbation, and health-related quality of life have all been defined as critical outcomes. ${ }^{4}$ Dyspnea was the main factor in determining patients' mask preferences, while objective sleep quality and gas exchange did not have an impact on this aspect. In this regard, it has previously been suggested that the patient's preferred choice of interface serves as an effective basis for the selection of interface for long-term NIV treatment. ${ }^{7}$ This is clearly supported by the current findings. 

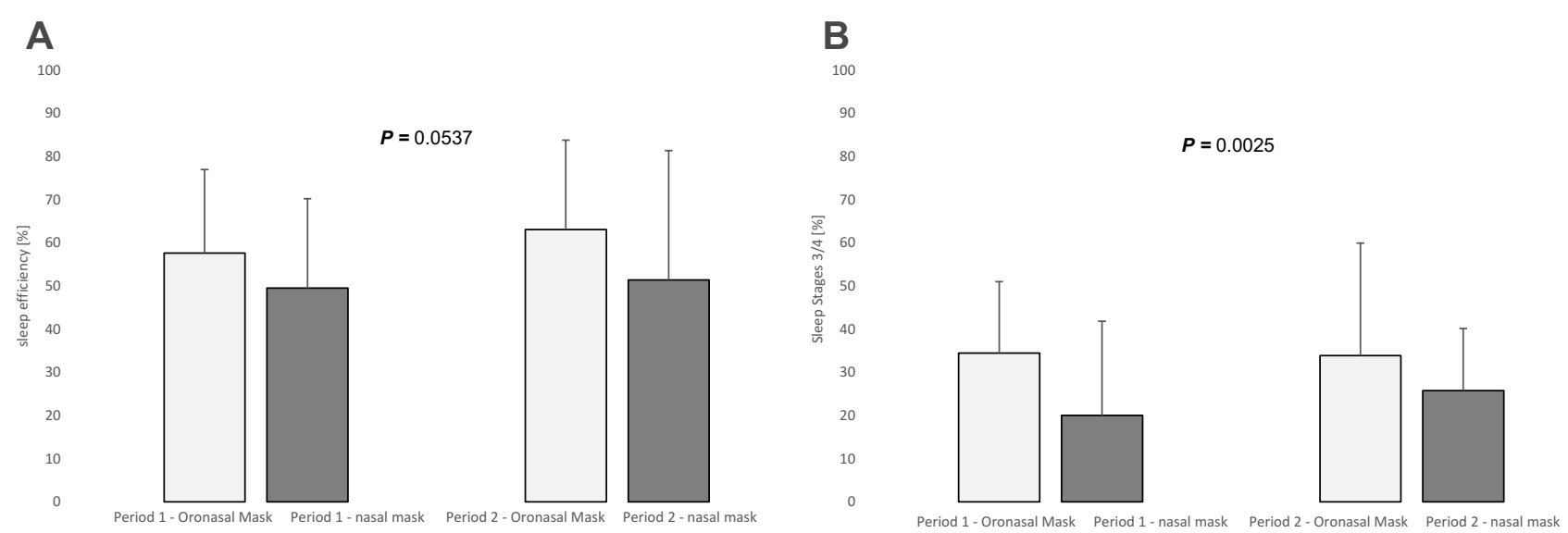

Figure 2 (A) Relative proportions of sleep efficiency (mean \pm SD) with oronasal versus nasal masks (primary endpoint). (B) Relative proportions of stage-3/4 sleep (mean \pm $\mathrm{SD})$ with oronasal versus nasal masks (secondary endpoint).

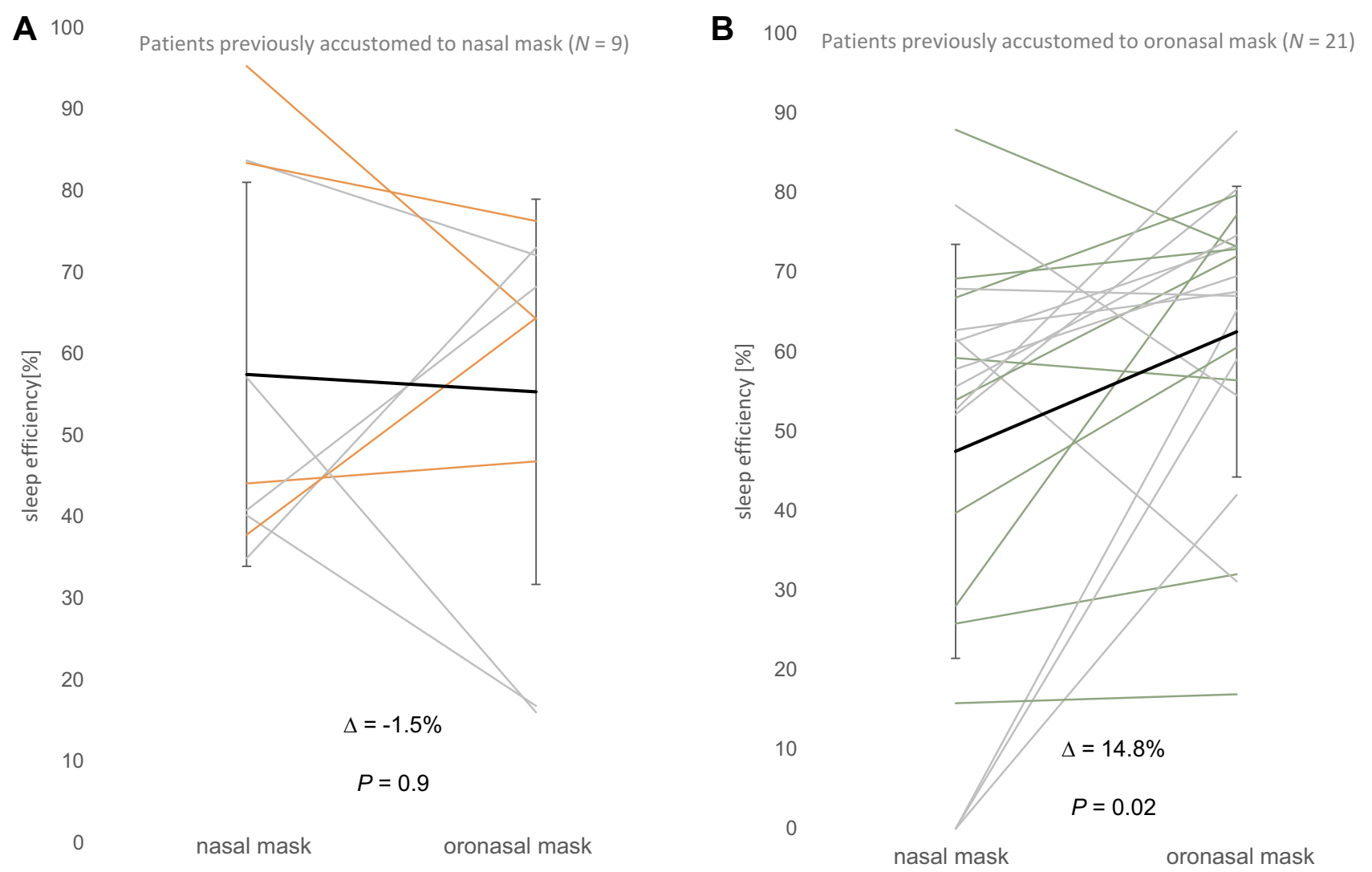

Figure 3 (A) Relative proportions of sleep efficiency (mean \pm SD) with oronasal versus nasal masks in patients who were already accustomed to a nasal mask at study inclusion. Patients who had finally changed the interface are given in orange. (B) Relative proportions of sleep efficiency (mean \pm SD) with oronasal versus nasal masks in patients who were already accustomed to an oronasal mask at study inclusion. Patients who had finally changed the interface are given in green.

The current study has several limitations. Firstly, patients were already familiar with either a nasal or an oronasal mask, since they were not NIV-naive prior to study inclusion. Furthermore, more patients had already received an oronasal mask for long-term NIV. Therefore, a bias regarding the impact of the mask the patients was accustomed to can certainly not be excluded, since changing the mask after acclimatization to the complementary mask could negatively influence subjective acceptance and subsequent sleep quality. However, following mask exchange in both directions as frequently observed, not only deteriorations, but also improvements in both sleep 


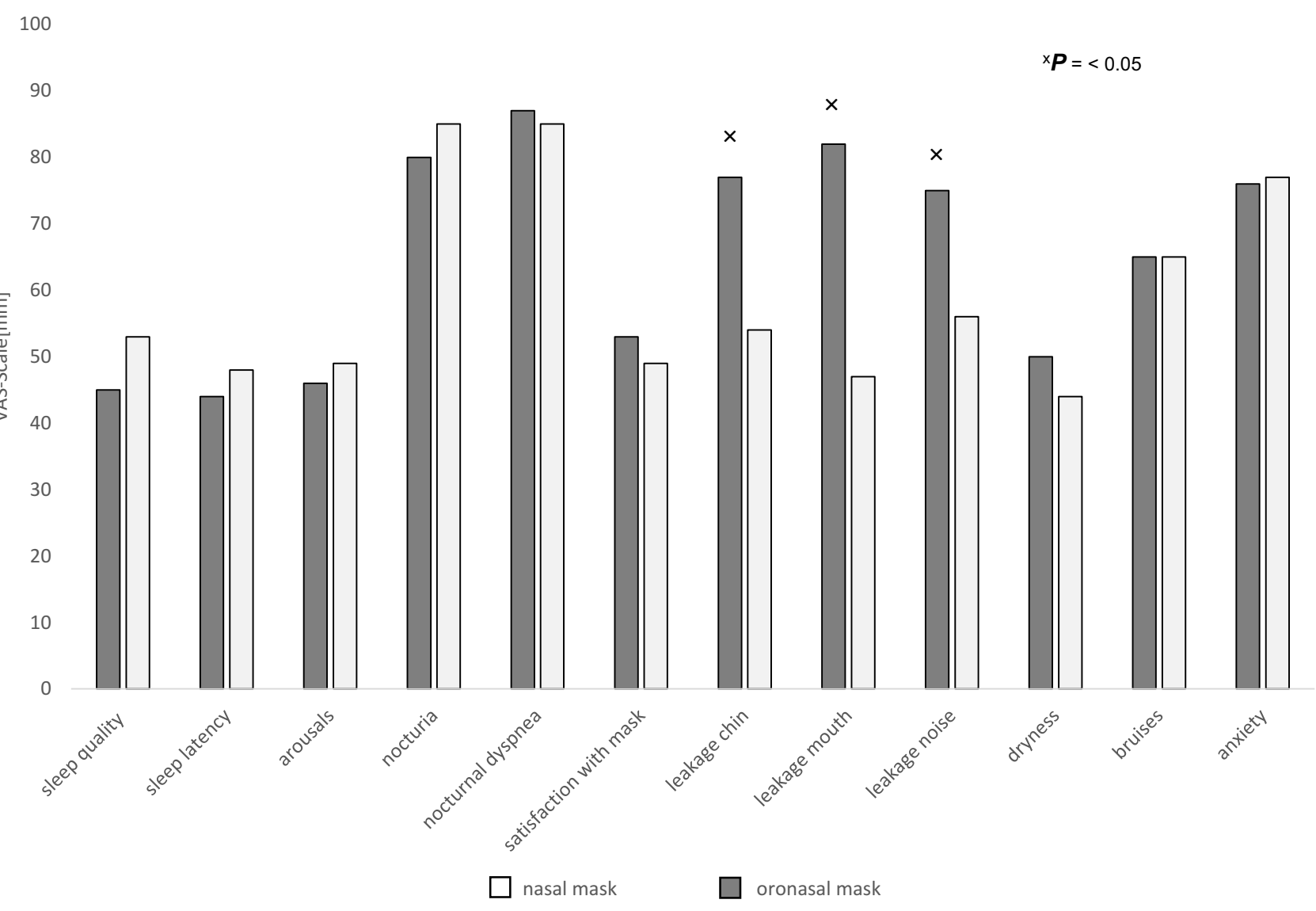

Figure $4 \mathrm{~A}$ visual analogue scale depicting the results of the subjective sleep survey on mask preference for nasal versus oronasal masks $($ Higher scores $=$ does apply; lower scores $=$ does not apply).

Abbreviation: VAS, visual analogue scale.

quality and nocturnal gas exchange were observed on an individual basis when switching from the interface the patients were accustomed to the complementary one. Notably, more than $40 \%$ of patients decided for themselves to continue long-term NIV with the mask that they were not already familiar with, regardless of the type of interface they had used prior to study inclusion.

Secondly, leakages during nocturnal NIV were only assessed subjectively and qualitatively, not quantitatively, even though significant leakage is particularly known to occur during HI-NIV. ${ }^{13}$ However, the type of interface is thought to affect nocturnal leakage. Accordingly, leakage can occur via an open mouth in patients fitted with a nasal mask, or via the mask itself when it is not fitted in an airtight manner, which is true both interface types; this is suggested to be dependent on the mask circumference, which is bigger in oronasal masks. Interestingly, subjective acceptance of the interface with regard to leakage was better when a nasal mask was used, even though this type of interface does not cover the mouth. This could indicate that mask leakage is subjectively more important than mouth leakage, and may hence play a role in determining interface acceptance.

Thirdly, this crossover study only assessed the shortterm effects of two different interfaces over two consecutive nights. It therefore remains unclear how the choice of the interface affects long-term and critical outcomes as defined by the ERS guidelines. ${ }^{4}$ Given that individual differences in ventilation quality were observed related to the type of the interface, the choice of the interface might also influence long-term and critical outcomes, and this should be verified by future trials.

In conclusion, nasal and oronasal masks are generally comparable in terms of their ability to deliver highintensity non-invasive ventilation to COPD patients. While a trend towards improved objective sleep quality was observed in patients who were fitted with an oronasal mask, less leakage impairment was subjectively reported by patients when they wore a nasal mask. Despite this, the evident advantages and disadvantages associated with 


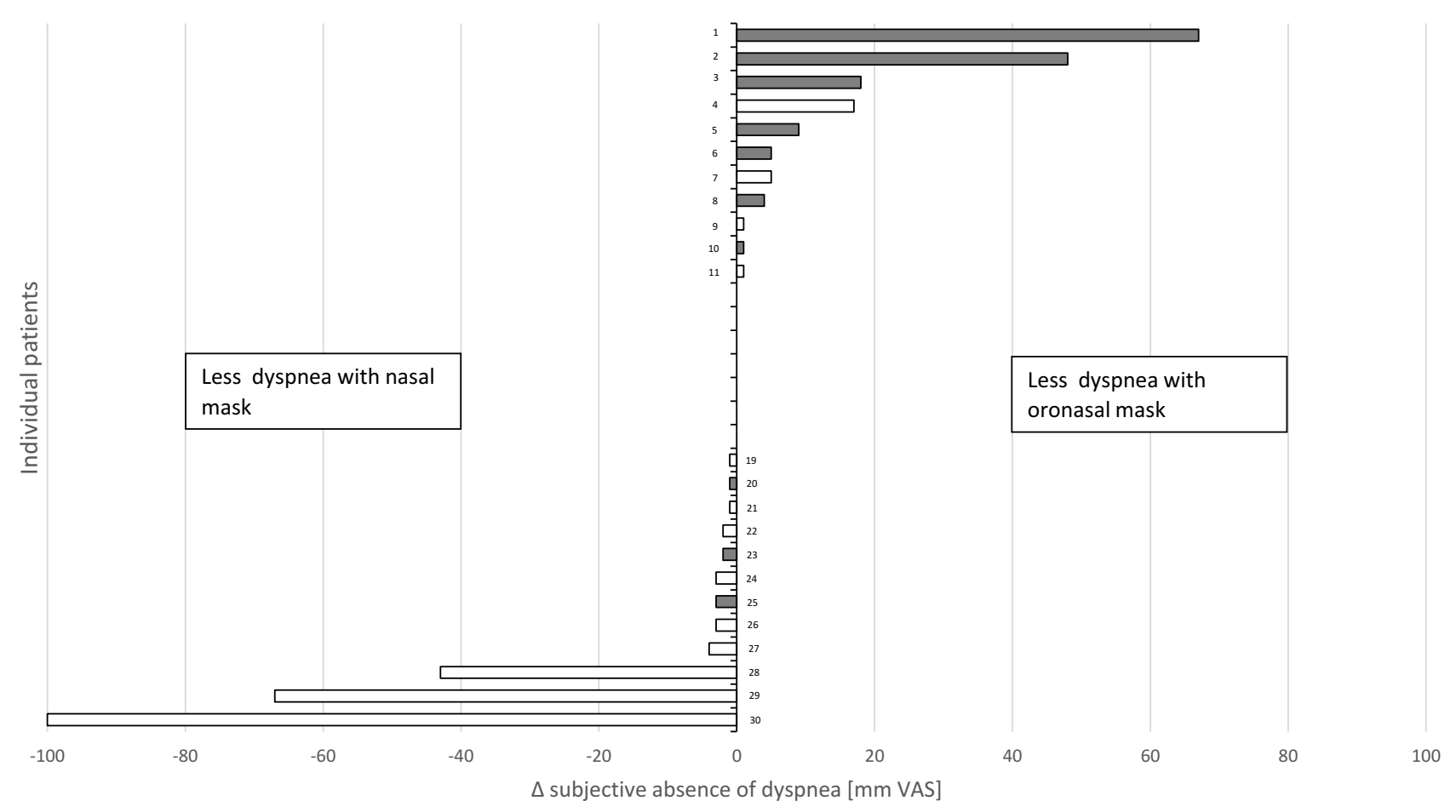

Figure 5 Individual subjective absence of dyspnea under each mask interface. Grey columns: patient favored oronasal mask. White columns: patient favored nasal mask.

nasal and oronasal masks varied broadly amongst individual patients, particularly in relation to the different subjective and objective parameters of sleep and ventilation quality. This occurred regardless of the type of interface the patient was already accustomed to. Finally, more than $40 \%$ of patients requested to switch from their usual interface to the alternative mask, irrespective of their sleep quality or control of nocturnal hypoventilation. Indeed, the patient's wish to continue long-term non-invasive ventilation with a specific interface is likely to depend on its ability to prevent dyspnea during nocturnal non-invasive ventilation.

\section{Abbreviation}

BMI, body mass index; COPD, Chronic obstructive pulmonary disease; ERS, European Respiratory Society; HI-NIV, high-intensity non-invasive ventilation; NIV, non-invasive ventilation; $\mathrm{PCO}$ 2, partial pressure of carbon dioxide; $\mathrm{PtcCO} 2$, partial pressure of transcutaneous carbon dioxide; PSG, polysomnography; REM, rapid eye movement; SD, standard deviation; VAS, visual analogue scale.

\section{Ethical Data Sharing Statement}

The authors do not intend to share individual deidentified participant data. The authors do only, without exception, share anonymized data with written permission given by each participant. The authors intend to publish an original contribution and the online data supplement and will not share any other information concerning this trial on other platforms. The data will be accessible through the publishing journal.

\section{Acknowledgments}

We acknowledge all participants for the effort they devoted to this study. Furthermore, we thank Dr Sandra Dieni for helpful comments on the manuscript prior to submission as well as Christine Hamm for support in evaluating polysomnographic data. This article was previously submitted and accepted as an abstract for the ERS Congress 2020.

\section{Author Contributions}

All authors made substantial contributions to conception and design, acquisition of data, or analysis and interpretation of data; took part in drafting the article or revising it critically for important intellectual content; agreed to submit to the current journal; gave final approval of the version to be published; and agree to be accountable for all aspects of the work.

\section{Funding}

A research grant was provided by VitalAire $\mathrm{GmbH}$ (VitalAire GmbH, Norderstedt, Germany). The authors state that neither the study design, results, interpretation 
of the findings, nor any other subject discussed in the submitted manuscript was dependent on financial support.

\section{Disclosure}

JCC received speaking fees and travel grants from companies dealing with mechanical ventilation products (VitalAire Germany; Löwenstein Medical; Vivisol). SBS received travel grants from companies dealing with mechanical ventilation products (Löwenstein Medical, Phillips Respironics). FSM received speaking fees from companies dealing with mechanical ventilation products (Vital Aire; Löwenstein Medical; Weinmann; Vivisol; Phillips Respironics). JHS received speaking fees from companies dealing with mechanical ventilation products (Heinen und Löwenstein; VitalAire; Vivisol; Weinmann Deutschland; Breas Medical; Boehringer Ingelheim; SenTec AG; Santis GmbH; Linde Deutschland; Keller Medical $\mathrm{GmbH}$ ). CS reports grants from Cologne Merheim Hospital, Department of Pneumology, Kliniken der Stadt Köln. WW received speaking fees from companies dealing with mechanical ventilation products (Löwenstein Medical, Vital Aire, Weinmann; Vivisol; Phillips Respironics). The Cologne study group (DSM, JCC, SBS, FSM, JHS, WW) received open research grants from Weinmann/Germany, Vivisol/Germany, Heinen und Löwenstein/Germany, VitalAire/Germany, and Phillips Respironics/USA. The authors report no other conflicts of interest in this work.

\section{References}

1. Goldberg A. Clinical indications for noninvasive positive pressure ventilation in chronic respiratory failure due to restrictive lung disease, COPD, and nocturnal hypoventilation - a consensus conference report. Chest. 1999;116(2):521-534. doi:10.1378/chest.116.2.521

2. Windisch W, Geiseler J, Simon K, Walterspacher S, Dreher M, on behalf of the Guideline C. German national guideline for treating chronic respiratory failure with invasive and non-invasive ventilation: revised edition 2017 - part 1. Respiration. 2018;96(1):66-97. doi: $10.1159 / 000488001$

3. Windisch W, Geiseler J, Simon K, Walterspacher S, Dreher M, on behalf of the Guideline C. German national guideline for treating chronic respiratory failure with invasive and non-invasive ventilationrevised edition 2017: part 2. Respiration. 2018;96(2):171-203. doi: $10.1159 / 000488667$

4. Ergan B, Oczkowski S, Rochwerg B, et al. European Respiratory Society guidelines on long-term home non-invasive ventilation for management of COPD. Eur Respir J. 2019;54. doi:10.1183/ 13993003.01003-2019

5. Schwarz SB, Magnet FS, Windisch W. Why high-intensity NPPV is favourable to low-intensity NPPV: clinical and physiological reasons. COPD. 2017;14(4):389-395. doi:10.1080/15412555.2017.1318843

6. Windisch W, Haenel M, Storre JH, Dreher M. High-intensity non-invasive positive pressure ventilation for stable hypercapnic COPD. Int J Med Sci. 2009;6:72-76. doi:10.7150/ijms.6.72
7. Fernandez R, Cabrera C, Rubinos G, et al. Nasal versus oronasal mask in home mechanical ventilation: the preference of patients as a strategy for choosing the interface. Respir Care. 2012;57 (9):1413-1417. doi:10.4187/respcare.01500

8. Willson GN, Piper AJ, Norman M, et al. Nasal versus full face mask for noninvasive ventilation in chronic respiratory failure. Eur Respir J. 2004;23(4):605-609. doi:10.1183/090319 36.04.00051604

9. Callegari J, Magnet FS, Taubner S, et al. Interfaces and ventilator settings for long-term noninvasive ventilation in COPD patients. Int J Chron Obstruct Pulmon Dis. 2017;12:1883-1889. doi:10.2147/COPD.S132170

10. Crimi C, Noto A, Princi P, et al. Domiciliary non-invasive ventilation in COPD: an international survey of indications and practices. COPD. 2016;13(4):483-490. doi:10.3109/ 15412555.2015 .1108960

11. Lloyd-Owen SJ, Donaldson GC, Ambrosino N, et al. Patterns of home mechanical ventilation use in Europe: results from the Eurovent survey. Eur Respir J. 2005;25:1025-1031. doi:10.1183/ 09031936.05.00066704

12. Schwarz SB, Callegari J, Hamm C, Windisch W, Magnet FS. Is outpatient control of long-term non-invasive ventilation feasible in chronic obstructive pulmonary disease patients? Respiration. 2018;95 (3):154-160. doi:10.1159/000484569

13. Dreher M, Storre JH, Schmoor C, Windisch W. High-intensity versus low-intensity non-invasive ventilation in patients with stable hypercapnic COPD: a randomised crossover trial. Thorax. 2010;65 (4):303-308. doi:10.1136/thx.2009.124263

14. Storre JH, Matrosovich E, Ekkernkamp E, et al. Home mechanical ventilation for COPD: high-intensity versus target volume noninvasive ventilation. Respir Care. 2014;59(9):1389-1397. doi:10.4187/ respcare. 02941

15. Singh D, Agusti A, Anzueto A, et al. Global strategy for the diagnosis, management, and prevention of chronic obstructive lung disease: the GOLD science committee report 2019. Eur Respir J. 2019;53(5):1900164. doi:10.1183/13993003.00164-2019

16. Patel AR, Patel AR, Singh S, Singh S, Khawaja I. Global initiative for chronic obstructive lung disease: the changes made. Cureus. 2019;11:e4985.

17. Mokhlesi B, Masa JF, Brozek JL, et al. Evaluation and management of obesity hypoventilation syndrome. An official American Thoracic Society Clinical Practice Guideline. Am J Respir Crit Care Med. 2019;200(3):e6-e24. doi:10.1164/rccm.201905-1071ST

18. Masa JF, Pepin J-L, Borel J-C, Mokhlesi B, Murphy PB, SanchezQuiroga MÁ. Obesity hypoventilation syndrome. Eur Respir Rev. 2019;28(151):28. doi:10.1183/16000617.0097-2018

19. Quanjer PH, Tammeling GJ, Cotes JE, Pedersen OF, Peslin R, Yernault J-C. Lung volumes and forced ventilatory flows. Report working party standardization of lung function tests, European Community for steel and coal. Official Statement of the European Respiratory Society. Eur Respir J Suppl. 1993;6(Suppl 16):5-40. doi:10.1183/09041950.005s 1693

20. Berry RB, Budhiraja R, Gottlieb DJ, et al., American Academy of Sleep M. Rules for scoring respiratory events in sleep: update of the 2007 AASM manual for the scoring of sleep and associated events. Deliberations of the sleep apnea definitions task force of the American Academy of Sleep Medicine. J Clin Sleep Med. 2012;8 (05):597-619. doi:10.5664/jcsm.2172

21. Rechtschaffen AKA. A Manual of Standardized Terminology, Techniques and Scoring System for Sleep Stages in Human Subjects. Washington DC: National Institutes of Health; 1968.

22. Dreher M, Ekkernkamp E, Walterspacher S, et al. Noninvasive ventilation in COPD: impact of inspiratory pressure levels on sleep quality. Chest. 2011;140(4):939-945. doi:10.1378/chest.110253 
23. Windisch W, Storre JH, Sorichter S, Virchow JC Jr. Comparison of volume- and pressure-limited NPPV at night: a prospective randomized cross-over trial. Respir Med. 2005;99(1):52-59. doi:10.1016/j. rmed.2004.05.009

24. Tuggey JM. Randomised crossover study of pressure and volume non-invasive ventilation in chest wall deformity. Thorax. 2005;60 (10):859-864. doi:10.1136/thx.2005.041327
25. Moher D, Schulz KF, Altman DG. The CONSORT statement: revised recommendations for improving the quality of reports of parallel-group randomised trials. Lancet. 2001;357 (9263):1191-1194. doi:10.1016/S0140-6736(00)04337-3

\section{Publish your work in this journal}

The International Journal of COPD is an international, peer-reviewed journal of therapeutics and pharmacology focusing on concise rapid reporting of clinical studies and reviews in COPD. Special focus is given to the pathophysiological processes underlying the disease, intervention programs, patient focused education, and self management protocols. This journal is indexed on PubMed Central, MedLine and CAS. The manuscript management system is completely online and includes a very quick and fair peer-review system, which is all easy to use. Visit http://www.dovepress.com/testimonials.php to read real quotes from published authors.

Submit your manuscript here: https://www.dovepress.com/international-journal-of-chronic-obstructive-pulmonary-disease-journal 